\title{
Crisis de pareja de hecho y animales de compañía. Sentencias en Cataluña, anteriores a la propuesta de reforma del Código Civil de 20 de abril de 2021
}

\author{
Miryam Olivera Oliva \\ Abogada del llustre Colegio de Abogados de Barcelona \\ Doctoranda en Derecho - Miembro del ICALP
}

Recepción: Mayo 2021

Aceptación: Junio 2021

Cita recomendada. OLIVERA OLIVA, M., Crisis de pareja de hecho y animales de compañía. Sentencias en Cataluña, anteriores a la propuesta de reforma del Código Civil de 20 de abril de 2021, dA. Derecho Animal (Forum of Animal Law Studies) 12/2 (2021). - DOI https://doi.org/10.5565/rev/da.578

\section{Resumen}

El objeto del presente comentario es analizar la Sentencia de 14 de marzo de 2018 del Juzgado de Primera Instancia $\mathrm{n}^{\circ} 9$ de Barcelona y la Sentencia fecha 6 de noviembre de 2019 del Juzgado de Primera Instancia e Instrucción $\mathrm{n}^{\circ} 7$ de Vilanova y la Geltrú, por ser ambas resoluciones judiciales dictadas en un procedimiento de juicio verbal tras la ruptura de pareja de hecho o pareja estable en los que el objeto de controversia es un animal de compañía, a los efectos de analizar el marco normativo aplicable en la Comunidad Autónoma de Cataluña así como determinar, si en ambos casos se ha atendido únicamente a la formulación negativa de que los animales no son cosas o, por el contrario, se ha atendido y reconocido específicamente la sentiencia a los animales de compañía y por ende, si ha influido dicha concepción para la resolución de ambos procedimientos. Ambas resoluciones son anteriores a la toma en consideración por parte del Pleno de los Diputados en su sesión de fecha 20 de abril de 2021, de la Proposición de Ley de modificación del Código Civil, la Ley Hipotecaria y la Ley de Enjuiciamiento Civil, sobre el régimen jurídico de los animales, presentada por el Grupo Parlamentario Socialista, publicada en el «BOCG ${ }^{1}$. Congreso de los Diputados», serie B, núm. 157-1, de 26 de marzo de 2021.

Palabras clave: animal compañía; animal doméstico; Código Civil de Cataluña; tenencia compartida; ser sensible; ser dotado de especial sensibilidad; sentiencia; Comunidad Autónoma Cataluña; pareja de hecho; pareja estable; Proposición de Ley; régimen jurídico animal. Abstract - Civil partnership crisis and companion animals: rulings in Catalonia prior to the proposal to
reform the Civil Code on 20th April 2021

The aim of this commentary is to analyse the sentence from the Court of First Instance $\mathrm{n}^{\circ} 9$ in Barcelona on 14th March 2018, and the sentence from the Civil and Criminal First Instance Court $\mathrm{n}^{\mathrm{o}} 7$ in Vilanova y la Geltrú on 6th November 2019, for both being legal rulings given in a verbal trial procedure following the breakup of a civil partnership or a stable partnership in which the point of controversy was a companion animal, to the effect of analysing the normative framework applicable in the autonomous community of Catalonia. This will determine whether in both cases only the negative formulation - that animals are not things - has been applied, or whether, to the contrary, companion animal sentience has been specifically recognised and applied and that, as a result, this conception has influenced the resolution of both proceedings. 
Both resolutions came before the plenary session on 20th April 2021 that considered the legal proposal to modify the Civil Code, the Mortgage Law and the Civil Procedure Rules, on the juridical rules for animals, presented by the socialist parliamentary group, published in the «BOCG ${ }^{1}$. Congreso de los Diputados», series B, number 157-1, on 26th March 2021.

Keywords: companion animal; domestic animal; Catalonian Civil Code; shared custody; sentient being; being endowed with special sensibility; sentience; Autonomous region of Catalonia; civil partnership; stable partnership; legislative proposal; legal status of animals.

\section{Sumario}

1. Hechos

2. Fundamentos de Derecho. Fallo

3. Conclusiones

4. Referencias

\section{Hechos}

En la SJPI n ${ }^{\circ} 9$ Barcelona, 14.3.2018 (MP: Antonio Lechón Hernández), la parte actora insta, tras la ruptura de la pareja de hecho, demanda de juicio verbal por la que peticiona la extinción de la comunidad de bienes entre ellos existentes en relación con la perra de raza Pastor Alemán llamada "Luna" y, en consecuencia, el establecimiento de un régimen de tenencia compartida por semanas alternas por ser ambos litigantes copropietarios de la perra Luna.

La parte demandada se opone a lo peticionado por la adversa, interesando que se desestime íntegramente la demanda interpuesta de contrario por entender que la parte actora no ostenta derecho dominical alguno sobre la perra Luna, al no ser propietaria de la misma.

En la SJPI n ${ }^{\circ} 7$ Vilanova i la Geltrú, 6.11.2019 (MP: José Villodre López) ${ }^{2}$, la parte actora insta, tras la ruptura de la pareja estable y al amparo de lo dispuesto en el art. 511-1.3, 552-10.1 y 552-11.5 y concordantes de la Ley 5/2006, de 10 de mayo, del Libro Quinto del Código Civil de Cataluña relativo a los derechos reales (en adelante "CCCat") ${ }^{3}$, acción de tenencia compartida de un perro de raza Beagle llamado "Pirata" por período iguales de quince días, por ostentar ambos litigantes título dominical sobre el mismo y, de forma subsidiaria, peticiona la atribución en exclusiva del mismo.

La parte demandada se opone interesando la desestimación integra de la demanda interpuesta de contraria por entender que en el presente proceso existe falta de legitimación activa de la parte actora por no ser la propietaria del perro Pirata; falta de legitimación pasiva del demandado por cuanto el perro Pirata pertenece en la actualidad a la compañera sentimental de éste; por cuanto la parte demandada puede ofrecer un entorno mejor para el perro Pirata y; por último, por ser de aplicación las reglas generales de la división de la cosa común, y en consecuencia, procede ofrecer a la adversa el pago que en su día se abonó para la compra del perro Pirata.

\footnotetext{
${ }^{2} \mathrm{https} / /$ www.poderjudicial.es/search/AN/openDocument/81cc883b70d1e1f8/20191219

${ }^{3}$ El art. 511-1.3 CCCat establece "los animales, que no se consideran cosas, están bajo la protección especial de las leyes. Solo se les aplican las reglas de los bienes en lo que permite su naturaleza".

El art. 552-10.1 CCCat establece "cualquier cotitular puede exigir, en cualquier momento y sin expresar sus motivos, la división del objeto de la comunidad".

El art. 552-11.5 CCCat establece "El objeto de la comunidad, si es indivisible, o desmerece notablemente al dividirse, o es una colección que integra el patrimonio artístico, bibliográfico o documental, se adjudica al cotitular o la cotitular que tenga interés en el mismo. Si existen más de uno, al que tenga la participación mayor. En caso de interés y participación iguales, decide la suerte. El adjudicatario o adjudicataria debe pagar a los demás el valor pericial de su participación, que en ningún caso tiene la consideración de precio ni de exceso de adjudicación. Si ningún cotitular tiene interés, se vende y se reparte el precio".
} 


\section{Fundamentos del Derecho. Fallo}

En la SJPI nº 9 Barcelona, 14.3.2018 (MP: Antonio Lechón Hernández), el Juzgador, tras la celebración de la oportuna comparecencia prevista en el artículo 440.1 de la Ley 1/2000, de 7 de enero, de Enjuiciamiento civil (en adelante "LEC") ${ }^{4}$, estima íntegramente la demanda interpuesta por la parte actora y, en consecuencia, acuerda la extinción de la comunidad de bienes ${ }^{5}$ existente entre las partes litigantes en relación con la perra Luna, estableciendo al efecto un régimen de tenencia compartida que, en defecto de acuerdo entre las partes, tendrá lugar por semanas alternas.

En este sentido mismo sentido falla la SJPI n ${ }^{\circ} 2$ Badajoz, 7.10.2020 (MP: Luis Romualdo Hernández Díaz-Ambrona) ${ }^{6}$ por cuanto "la solución propugnada de la tenencia compartida es correcta. Estamos ante un bien, el perro, indudable y esencialmente indivisible (art. 401 CC). Las opciones entonces serían la adjudicación del perro a uno de los dueños, con deber de indemnizar al otro (art. $404 \mathrm{CC}$ ), o el disfrute compartido (art. $394 \mathrm{CC}$ ). Como quiera que aquí no se ha instado por ninguno de los condueños del perro la primera posibilidad, es decir, la extinción de la comunidad mediante la entrega del animal a uno de ellos y la consiguiente compensación al otro, sólo cabe la alternativa de regular el disfrute del animal".

Siendo que la extinción de la comunidad de bienes debe producirse toda vez que esta situación de permanecer en comunidad no se reputa perpetua pues ya en el Derecho Romano, según palabras de la Dra. Giménez-Candela "la copropiedad era una situación temporal que podía ser resuelta a iniciativa de cualquiera de los copropietarios, mediante el ejercicio de una acción divisoria $[\ldots]$ a hacer partes de la cosa común y a declarar efectivamente propietarios a cada uno de los titulares de dichas partes ${ }^{7}$ ”.

Para ello el Juzgador se ampara en que los animales, de conformidad con lo dispuesto en el art. 511-1 del CCCat ${ }^{8}$, no se consideran cosas y, por lo tanto, sólo se les aplica las reglas de los bienes en lo que permita su propia naturaleza. Dicha formulación negativa de que los animales no son cosas lo sustenta en base a que los animales, -de conformidad con art. 2.2 del Decreto Legislativo 2/2008, de 15 de abril, por el que se aprueba el Texto Refundido de la Ley de Protección de los animales-, son seres vivos dotados de sensibilidad física y psíquica ${ }^{9}$, lo que se conoce comúnmente con la denominación de sentiencia, por transcripción del término inglés "sentience"

Además, el Juzgador reproduce lo dispuesto en la SAP Barcelona, 10.7.2014 (MP: Juan Miguel Jiménez de Parga Gastón) ${ }^{11}$ acerca de que los animales domésticos son seres vivos que se encuentra en el domicilio familiar, y atendiendo a su categoría, al tratarse de bienes muebles, pueden ser susceptibles de ser reclamados en propiedad, esto es, que en caso de copropiedad puede instarse el ejercicio de acciones tendentes a obtener la división de la cosa común y el uso compartida, sin perjuicio de la utilización por el otro comunero. Para ello, aduce que se presume que existe copropiedad de los bienes de valor ordinario adquiridos a título oneroso durante el matrimonio destinados al uso familiar (art. 232-3.2 del CCCat ${ }^{12}$ ).

Es menester atender, cómo en este punto, el Juzgador se ciñe únicamente a la normativa obrante en nuestro ordenamiento jurídico obviando por completo para su argumentación tanto la doctrina y trabajos científicos ${ }^{13}$, así como el cambio de paradigma del régimen jurídico de los animales mediante la influencia,

\footnotetext{
${ }^{4}$ El art. 440.1 LEC establece "contestada la demanda y, en su caso, la reconvención o el crédito compensable, o transcurridos los plazos correspondientes, el letrado de la Administración de Justicia, cuando haya de celebrarse vista de acuerdo con lo expresado en el artículo 438, citará a las partes a tal fin dentro de los cinco días siguientes. La vista habrá de tener lugar dentro del plazo máximo de un mes. En la citación se fijará el día y hora en el que haya de celebrarse la vista, y se informará a las partes de la posibilidad de recurrir a una negociación para intentar solucionar el conflicto, incluido el recurso a una mediación, en cuyo caso éstas indicarán en la vista su decisión al respecto y las razones de la misma. [...]".

${ }^{5}$ Según palabras de BERCOVITZ RODRÍGUEZ-CANO, Comentarios al Código Civil (Tomo III), vid. p. 3235 "podríamos decir que del término cotitularidad deriva el de comunidad, pues lo que define la comunidad es la titularidad común sobre un mismo derecho de varios sujetos. Por ello, se ha destacado que la situación de comunidad es un efecto legal automático derivado de la cotitularidad de un derecho. En tal sentido, siendo dos o más sujetos titulares pro indiviso de un mismo derecho, quedará constituida entre ellos una comunidad".

${ }^{6} \mathrm{http}: / /$ www.poderjudicial.es/search/AN/openDocument/1bda2019841b8f70/20101021

${ }^{7}$ GIMÉNEZ-CANDELA, T., Derecho privado romano, Tirant lo Blanch (Valencia 2020), vid. p. 203.

${ }^{8}$ Vid. supra 3

${ }^{9}$ En este sentido, en el art. 2.2 de la Ley de Protección de los animales de Cataluña se acordó que "los animales son seres vivos dotados de sensibilidad física y psíquica, así como de movimiento voluntario, y deben recibir el trato que, atendiendo básicamente a sus necesidades etológicas, procure su bienestar".

10 Para un mayor estudio, GIMÉNEZ-CANDELA, T., Dignidad, Sentiencia, Personalidad: relación jurídica humano-animal, en dA Derecho Animal (Forum of Animal Law Studies) 9/2 (2018). DOI: https://doi.org/10.5565/rev/da.346

${ }^{11} \mathrm{http}: / /$ www.poderjudicial.es/search/AN/openDocument/d8e11 ee0d224d959/20140929

${ }^{12} \mathrm{El}$ art. 232-3.2 CCCat establece "si los bienes adquiridos a título oneroso durante el matrimonio son bienes muebles de valor ordinario destinados al uso familiar, se presume que pertenecen a ambos cónyuges por mitades indivisas, sin que prevalezca contra esta presunción la mera prueba de la titularidad formal".

13 Tales como todas las publicaciones obrantes en la revista dA. Derecho Animal (Forum of Animal Law Studies) así como las 192 Derecho Animal. Forum of Animal Law Studies, vol. 12/2
} 
inicialmente del Protocolo no 33 sobre la Protección y el Bienestar de los Animales de 1997 anexado al Tratado Constitutivo de la Comunidad Europea (Tratado de Ámsterdam) que fue el primer texto legal de la Unión Europea (en adelante "UE") que reconoció respetar el bienestar de los animales como seres sensibles y, posteriormente el art. 13 del Tratado de Funcionamiento de la Unión Europea (en adelante "TFUE") ${ }^{14}$ así como los cambios legislativos producidos en los demás ordenamientos jurídicos europeos como Francia y Portugal ${ }^{15}$, a los que podría haber hecho referencia para enriquecer su fundamentación jurídica por ser los primeros países, junto con Colombia ${ }^{16}$, en reconocer la sentiencia animal en sus propios códigos civiles ${ }^{17} \mathrm{o}$ bien, los cambios producidos en los países como Austria, Alemania y Suiza ${ }^{18}$ que fueron los primeros países europeos en impulsar el movimiento de "descosificación" animal ${ }^{19}$, dotando por otro lado de mandato constitucional la protección animal mediante la dignidad y vida así como bienestar del animal.

Sin embargo, lejos de atender o reseñar sucintamente lo anterior para motivar jurídicamente su fallo, el Juez a quo reproduce una resolución judicial dictada por la Audiencia Provincial de Barcelona en el año 2014 en el marco de un proceso de familia -disolución matrimonial por divorcio-, que aplica normativa específica destinada a dicha materia para justificar la existencia de una copropiedad respecto la perra Luna junto con la práctica de la prueba consistente en los interrogatorios de la partes y documental, no motivando la misma atendiendo a su propia sentiencia y convivencia conjunta con ambos litigantes.

Por otro lado, en la SJPI no 7 Vilanova i la Geltrú, 6.11.2019 (MP: José Villodre López), el Juzgador, tras la celebración de la oportuna comparecencia prevista en el art. 440.1 de la LEC, alcanza igual fallo que la SJPI no 9 Barcelona, 14.3.2018 (MP: Antonio Lechón Hernández) al acordar la tenencia compartida del animal de compañía toda vez que estima íntegramente la demanda interpuesta por la parte actora, acordando así la tenencia compartida del perro Pirata por períodos iguales de quince días y la obligación de sufragar por partes iguales entre ellos, los gastos veterinarios y otros de naturaleza obligatoria que se pudieran devengar por disposición legal en relación con el perro Pirata.

En este caso, y a diferencia de la fundamentación jurídica mantenida en la SJPI $n^{\circ} 9$ Barcelona, 14.3.2018 (MP: Antonio Lechón Hernández) anteriormente analizada, el Juzgador tras resolver las cuestiones previas de legitimación de las partes, toma en consideración la vinculación emocional y lazos afectivos creados entre el animal de compañía y los litigantes, argumentando para ello que la mentada relación y vinculación emocional no es comparable con el derecho de propiedad sobre otro tipo de bienes, así como la actitud y aptitud de ambas partes para atender a los cuidados del perro Pirata, concluyendo que no sería una solución adecuada una atribución exclusiva a favor de uno de los litigantes indemnizando al otro con una cantidad de dinero del procedimiento general previsto en el art. 552-11 del CCCat.

En cuanto a la relación y vinculación emocional entre el animal de compañía y las personas al que hace referencia la resolución judicial reseñada debe enlazarse con el concepto del Código Civil Austríaco ("ABGB, Allgemeines Bürgerliches Gesetzbuch" ${ }^{20}$ por ser el primero que introdujo la relación emocional / afectiva con el animal como principio para determinar el régimen de tratamiento del mismo, al imponer un cambio en el estatuto de los animales consistente en suprimir con rango de ley el estatuto de los animales como cosas para pasar a una formulación negativa ${ }^{21}$, esto es, el Código Civil y, al Código de ejecución ${ }^{22}$ en cuanto a la inembargabilidad de los animales de compañía que no se destinase a la venta - con motivo del cambio introducido en el BGB-, aunque, y según palabras textuales de la Dra. Giménez-Candela "ya en 1988 el ABGB

\footnotetext{
investigaciones y proyectos llevados a cabo desde el International Center for Animal Law and Policy (ICALP) en defensa de los derechos de los animales.

${ }^{14}$ El art. 13 TFUE establece "al formular y aplicar las políticas de la Unión en materia de agricultura, pesca, transporte, mercado interior, investigación y desarrollo tecnológico y espacio, la Unión y los Estados miembros tendrán plenamente en cuenta las exigencias en materia de bienestar de los animales como seres sensibles, respetando al mismo tiempo las disposiciones legales o administrativas y las costumbres de los Estados miembros relativas, en particular, a ritos religiosos, tradiciones culturales y patrimonio regional".

${ }^{15}$ Código civil francés, artículo 515-14.

Disponible en https://www.legifrance.gouv.fr/affichCode.do?cidTexte=LEGITEXT000006070721

Código civil portugués, artículo 201. ${ }^{\circ}-\mathrm{B}$.

Disponible en http://www.pgdlisboa.pt/leis/lei_mostra_articulado.php?nid=775\&tabela=leis

${ }^{16}$ Código civil de Colombia, artículo 655.

Disponible en http://www.secretariasenado.gov.co/senado/basedoc/codigo_civil.html

${ }^{17}$ Para un mayor estudio, GIMÉNEZ-CANDELA, T., Transición animal en España, Tirant lo Blanch (Valencia 2020), vid. p. 231238.

${ }^{18}$ Para un mayor estudio, GIMÉNEZ-CANDELA, Transición animal en España (cit.), vid. p. 244-250.

${ }^{19}$ En este punto, vid. GIMÉNEZ-CANDELA, La descosificación de los animales (I) y (II), en dA Derecho Animal (Forum of Animal Law Studies) 8/2 y 8/3 (2017). DOI: https://doi.org/10.5565/rev/da.250

${ }^{21}$ Según GIMÉNEZ-CANDELA, Transición animal en España (cit.), vid. p. 246, “en el art. 285a. ABGB se excluye expressis verbis al animal del concepto de cosa".

${ }^{22}$ Art. 250 EO (Exekutionsordnung) vid. https://www.ris.bka.gv.at/eli/rgbl/1896/79/P250/NOR40021412
} 
incluyó en la reforma de la ZPO, la inembargabilidad de los animales en atención al "especial vínculo afectivo" que les liga a la familia con la que conviven ${ }^{23}$ ".

Además, tras la práctica de la prueba, el Juzgador considera que se puede vislumbrar la situación dominical consistente en la copropiedad de los litigantes respecto del perro Pirata con motivo de la relación sentimental con convivencia entre ellos. Para ello, se ampara en que el perro Pirata "se trata de un ser vivo que acompaña e interactúa con sus propietarios, creándose estrechos lazos de afectividad mutua que deben ser conservados. Y no solo en pos de los derechos de cada uno de los propietarios sino también del propio animal".

En virtud de lo dispuesto en el art. 13 del TFUE ${ }^{24}$ que considera a los animales como seres sensibles, exhortando a los Estados miembros a que tengan plenamente en cuenta las exigencias en materia de bienestar de los animales ${ }^{25}$, trayendo a colación la normativa aplicable a la Comunidad Autónoma de Cataluña, esto es, el art. 511.1.3 del CCCat ${ }^{26}$ acerca de que los animales no se consideran cosas y art. 2.2 del Decreto Legislativo 2/2008, de 15 de abril, por el que se aprueba el Texto Refundido de la Ley de Protección de los animales ${ }^{27}$, acerca de la cualidad de los animales como seres vivos dotas de sensibilidad física y psíquica.

Lejos de encasillarse en la citada normativa, el Juez a quo crítica nuestro actual marco regulatorio al plasmar en sus Fundamentos de Derecho Cuarto que, pese a la remisión normativa del art. 511-1.3 del CCCat, existe una laguna en nuestro ordenamiento jurídico acerca del régimen jurídico de los animales por no existir regulación expresa que prevea qué sucede en situaciones de ruptura de pareja de hecho en relación con el animal de compañía ${ }^{28}$, argumentado el Juzgador para ello que:

Esta laguna debería ser colmada a la mayor brevedad pues, no se olvide, los perros forman parte de nuestra cotidianeidad, de nuestro entorno más cercano. Sirva al afecto un solo dota; según el cómputo realizado por la Asociación Nacional de Fabricantes de Alimentos para Animales de Compañía en 2017 había más de seis millones de perros en España, lo que implica que en el 40\% de los hogares españoles reside un perro. Con este panorama procede la fijación de un sistema de tenencia compartida que también implique la cobertura de los gastos.

Por último, el Juzgador, a modo de valoración, expresa ${ }^{29}$ que a su propio juicio, la periodicidad ideal en la tenencia compartida del perro Pirata hubiera sido semanal en vez de quincenal, pero estando enjuiciando un procedimiento declarativo, no un proceso de familia que goza de mayor flexibilidad, debe primar el principio de justicia rogada que consagra el art. 216 y 218.1 de la LEC.

\section{Conclusión}

Ambas resoluciones judiciales analizadas han aplicado lo dispuesto en el Libro Quinto del CCCat.

Atendiendo a lo anterior, y a diferencia de la regulación de los animales previstos en el Código Civil (en adelante "CC") que prevé el régimen jurídico de los animales como $\operatorname{cosas}^{30}$, - sin perjuicio de que el Pleno de los Diputados, en su sesión de fecha 20 de abril de 2021, ha aprobado la toma en consideración de la Proposición de Ley de modificación del Código Civil, la Ley Hipotecaria y la Ley de Enjuiciamiento Civil, sobre el régimen jurídico de los animales, presentada por el Grupo Parlamentario Socialista, publicada en el «BOCG. Congreso de los Diputados», serie B, núm. 157-1, de 26 de marzo de 202131, Proposición de Ley que ya tuvo en el año 2017 un primer intento fallido a raíz de que se iniciara la tramitación de la misma cuando

\footnotetext{
${ }^{23}$ GIMÉNEZ-CANDELA, Transición animal en España (cit.), vid. p. 247.

${ }^{24}$ Vid. supra 14

${ }^{25}$ En este sentido, los países miembros de la UE deben ejecutar en su territorio nacional la normativa comunitaria en materia de bienestar animal.

Vid.https://www.mapa.gob.es/es/ganaderia/temas/produccion-y-mercados-ganaderos/bienestanimal/aspectos-generales/

${ }^{26}$ Vid. supra 8

${ }^{27}$ Vid. supra 9

${ }^{28}$ Circunstancia ésta que se ha hecho eco en los medios de comunicación, vid. https://elpais.com/economia/2017/12/12/mis_derechos/1513074922_591231.html

Para mayor estudio acerca de qué sucede en situaciones de ruptura de pareja de hecho en relación con el animal de compañía vid. CERDEIRA BRAVO DE MANSILLA, G., Crisis familiares y animales domésticos, Reus (Madrid 2020). SILLERO CROVETTO, B., Animales de compañía y crisis matrimoniales: marco normativo y decisiones judiciales, en Diario La Ley no 9532 (2019). CASAS DÍAZ L., CAMPS I VIDELLET X., Las crisis matrimoniales y los animales de compañía: una aproximación práctica desde el ejercicio de la abogacía. dA. Derecho Animal (Forum of Animal Law Studies) 10/1 (2019 - DOI https://doi.org/10.5565/rev/da.397

${ }^{29}$ En el FFDD $4^{\circ}$ el Juzgador expone, cuya literalidad se transcribe, que "Aunque a mi juicio la periodicidad ideal sería la semanal, no se puede obviar que no estamos en un procedimiento de familia dotado de una mayor flexibilidad rogada que consagran los art. 216 y 218.1 LEC. En consecuencia, salvo pacto en contrario, cada una de las partes podrá disfrutar de la compañía de Piratas durante 15 días alternos".

${ }^{30}$ Art. 333 CC prevé "todas las cosas que son o pueden ser objeto de apropiación se consideran como bienes muebles o inmuebles".

${ }^{31}$ Disponible en: https://www.congreso.es/public_oficiales/L14/CONG/BOCG/B/BOCG-14-B-157-1.PDF\#page=1 
el pleno del Congreso de los Diputados, en fecha 14 de febrero de 2017, aprobó por unanimidad instar al Gobierno modificar el régimen jurídico de los animales ${ }^{32}$, es precisamente la Comunidad Autónoma de Cataluña -siendo a día de hoy sólo esta Comunidad Autónoma en todo el territorio español- donde por primera vez un texto legislativo civil en España prevé que los animales son no-cosas (art. 511-1.3 del CCCat), eso sí, quedando igualmente sujetos a las reglas de los bienes en lo que permita su propia naturaleza y bajo la protección especial de las leyes. Sumándose por tanto la Comunidad Autónoma de Catalunya a la corriente iniciada por los países como Austria (1988), Alemania (1990) y Suiza (2004), acerca de que los animales son no-cosas modificando así el régimen jurídico de los animales en sus propios Códigos Civiles. ${ }^{33}$

Esto supone que ambas resoluciones judiciales hayan reseñado de forma adecuada la formulación negativa de que $<$ los animales no son cosas $>$, cuya entrada en vigor mediante el CCCat se produjo en el año 2006. De ahí la importancia de que las resoluciones objeto de comentario atiendan a que los animales no son cosas, pero no puedan aplicar directamente la cualidad de seres sentientes sin traer a colación lo dispuesto en la Ley de protección de los animales de Cataluña o normativa europea e internacional, al no contemplar el citado código tal concepción.

Sin embargo, debe atenderse que, pese a dicha formulación negativa, el régimen jurídico de los animales de compañía reza igualmente obsoleto en supuestos de crisis de pareja de hecho, -no sólo en los procesos de familia al no contener regulación específica alguna-, sino en procesos declarativos donde se peticiona precisamente la tenencia compartida o exclusiva del mismo, por cuanto no existe regulación específica al respecto, debiendo de remitirnos específicamente a lo dispuesto en nuestro CCCat acerca de la regulación de la división de comunidad de bienes, siendo esta la acción ejercitada a la cual se derivan perceptivamente dichas controversias fuera del proceso de familia.

Es menester en este punto reseñar que con la pretendida y, hoy en tramitación, reforma del régimen jurídico de los animales a través de la Proposición de Ley de modificación del Código Civil, la Ley Hipotecaria y la Ley de Enjuiciamiento Civil ${ }^{34}$, se pretende modificar, en lo que afecta al presente comentario de sentencias, el art. 333 CC para dotar que los animales son seres vivos dotados de sensibilidad y que sólo se les aplique el régimen jurídico de los bienes y de las cosas en la medida en que sea compatible con su propia naturaleza y con las disposiciones destinadas a su protección ${ }^{35}$, sin perjuicio de que la Exposición de motivos de tal Proposición de Ley prevea que "lo deseable $<<$ de lege ferenda $>>$ es que ese régimen protector vaya extendiéndose progresivamente a los distintos ámbitos en que intervienen los animales, y se vaya restringiendo con ello la aplicación supletoria del régimen jurídico de las cosas" e introducir normas relativas a las crisis matrimoniales ${ }^{36}$ a los efectos de regularizar el régimen de tenencia de los animales de compañía, sentando así

\footnotetext{
${ }^{32}$ Disponible en:

http://www.congreso.es/portal/page/portal/Congreso/Congreso/Iniciativas?_piref73_2148295_73_1335437_1335437.next_page=/w $\mathrm{c} /$ servidorCGI\&CMD $=$ VERLST\&BASE $=\mathrm{IW} 12 \& \mathrm{FMT}=\mathrm{INITXDSS} . \mathrm{fmt} \& \mathrm{DOCS}=1-$

$1 \&$ DOCORDER $=$ FIFO\&OPDEF=ADJ\&QUERY=\%28122\%2F000134*.NDOC. $\% 29$

33 El art. 641a ZGB (Código Civil suizo) establece que los animales no son cosas ("Nicht Sachen"). Disponible en: https://www.fedlex.admin.ch/eli/cc/24/233_245_233/de

El art. 285a. ABGB (Código Civil Austríaco) establece que los animales no son cosas. Disponible en: https://www.ris.bka.gv.at/Dokument.wxe?Abfrage=Bundesnormen\&Dokumentnummer=NOR12018011

El art. 90a. BGB (Código Civil Alemán) establece que los animales no son cosas. Disponible en: https://www.gesetze-iminternet.de/bgb/90a.html

${ }^{34}$ Vid. supra 31.

${ }^{35}$ La Proposición de Ley de modificación del Código Civil, la Ley Hipotecaria y la Ley de Enjuiciamiento Civil, sobre el régimen jurídico de los animales publicada en el «BOCG. Congreso de los Diputados», serie B, núm. 157-1, de 26 de marzo de 2021 prevé modificar la rúbrica del Libro Segundo del Código Civil y de su Título en los términos siguientes: "Artículo 333. 1. Los animales son seres vivos dotados de sensibilidad. Solo les será aplicable el régimen jurídico de los bienes y de las cosas en la medida en que sea compatible con su naturaleza y con las disposiciones destinadas a su protección. [...] Artículo 333 bis. Todas las cosas que son o pueden ser objeto de apropiación se consideran como bienes muebles o inmuebles. También pueden ser objeto de apropiación los animales, con las limitaciones que se establezcan en las normas legales y en la medida en que no lo prohíban.» [...]"

${ }^{36}$ La Proposición de Ley de modificación del Código Civil, la Ley Hipotecaria y la Ley de Enjuiciamiento Civil, sobre el régimen jurídico de los animales publicada en el «BOCG. Congreso de los Diputados», serie B, núm. 157-1, de 26 de marzo de 2021 prevé modificar el Código Civil en los términos siguientes: "Artículo 90 c) el destino de los animales de compañía, en caso de que existan, teniendo en cuenta el interés de los miembros de la familia y el bienestar del animal, pudiendo preverse el reparto de los tiempos de convivencia y cuidado si fuere necesario, así como de las cargas asociadas al cuidado del animal; Artículo 91. En las sentencias de nulidad, separación o divorcio, o en ejecución de las mismas, el Juez, en defecto de acuerdo de los cónyuges o en caso de no aprobación del mismo, determinará conforme a lo establecido en los artículos siguientes las medidas que hayan de sustituir a las ya adoptadas con anterioridad en relación con los hijos, la vivienda familiar, el destino de los animales de compañía, las cargas del matrimonio, liquidación del régimen económico y las cautelas o garantías respectivas, estableciendo las que procedan si para alguno de estos conceptos no se hubiera adoptado ninguna. Estas medidas podrán ser modificadas cuando se alteren sustancialmente las circunstancias; Artículo 94 bis. La autoridad judicial confiará para su cuidado a los animales de compañía a uno o ambos cónyuges, y determinará, en su caso, la forma en la que el cónyuge al que no se le hayan confiado podrá tenerlos en su compañía, todo ello atendiendo al interés de los miembros de la familia y al bienestar del animal, con independencia de la titularidad dominical de este. Esta circunstancia se hará constar en el correspondiente registro de identificación de animales; y Artículo 103. $2^{\mathrm{a}}$ Determinar, atendiendo al interés de los
} 
criterios sobre los que los Tribunales deberán tomar la decisión de a quién otorgan la tenencia y cuidado del animal de compañía, atendiendo a su bienestar.

En cuanto a la SJPI ${ }^{\circ} 9$ Barcelona, 14.3.2018 (MP: Antonio Lechón Hernández), es menester remarcar que la fundamentación jurídica de la misma no destaca precisamente por su gran argumentación jurídica y aportación a la doctrina científica toda vez que nos encontramos ante un redactado básico y poco elocuente por hacer únicamente referencia a lo dispuesto en el art. 511-1.3 del CCCat y a la Ley de Protección Animales de Cataluña. Además, con una argumentación superflua hace especial remisión a la SAP Barcelona, 10.7.2014 (MP: Juan Miguel Jiménez de Parga) cuyo caso precisamente no es análogo al enjuiciado por tratarse de una disolución matrimonial por divorcio y no un proceso de división de la cosa común tras la extinción de la pareja de hecho, a la que precisamente deriva la cuestión a un proceso declarativo de acción de división de bienes comunes y liquidación de los mismos, en el supuesto de no haber acumulado tal acción al proceso matrimonial.

En otro orden de cosas, el Juzgador no trae a colación ni hace remisión a la doctrina y legislación europea al no reseñar el art. 13 del TFUE ni tan siquiera procede a motivar su fallo atendiendo al movimiento de descosificación animal al que socialmente España ${ }^{37}$ se sumó y, que se inició en Europa en la década de los 80 mediante la modificación del Código Civil Austríaco con la expresión negativa de que los animales son "no-cosas" 38 . No obstante, y pese a que a nivel jurídico no aporta mayor trascendencia que el fallo alcanzado, debe advertirse que la citada resolución judicial tuvo gran resonancia en los medios de comunicación por ser uno de los primeros casos en la Comunidad Autónoma de Cataluña donde se acordó la tenencia compartida de un animal de compañía tras la ruptura sentimental de sus propietarios ${ }^{39}$ y cuyos medios recogieron como el otorgamiento de una primera "custodia" compartida respecto un perro.

Por el contrario, la SJPI no 7 Vilanova i la Geltrú, 6.11.2019 (MP: José Villodre López) si supone, a diferencia de la anterior resolución, un avance en la fundamentación jurídica toda vez que el Juzgador parte de la premisa inicial que el animal de compañía "es un ser vivo que acompaña e interactúa con sus propietarios, creándose estrechos lazos de afectividad mutua que deben ser conservados" y ratifica la normativa que reconoce la sentiencia animal.

Esto es así por cuanto invoca lo dispuesto en el art. 13 del TFUE para acabar concluyendo que los Estados miembros deben tener en cuenta las exigencias en materia de bienestar animal y, tras la posterior invocación de cierta normativa autonómica que se ha reseñado anteriormente en el Apartado de Fundamentos de Derecho y Fallo, considera a los animales como seres sentientes -pese a que el Juzgador no lo explicite concretamente.

Además, se hace eco de la problemática actual en procesos de familia, por cuanto el ordenamiento jurídico de la Comunidad Autónoma de Cataluña (y lo mismo sucede con el estatal), no contiene regulación expresa que resuelva situaciones como las que nos ocupa, dejando a voluntad del Juez fallar a favor del interés del animal de compañía o ceñirse estrictamente a las normas de derecho de propiedad en cuanto a los derechos dominicales de los litigantes.

Sin duda, podemos afirmar que estamos ante una sentencia novedosa dentro de la Comunidad Autónoma de Cataluña por atender e interpretar la norma con la realidad social y la creciente necesidad de encontrar soluciones a un conflicto muy concurrente tras las rupturas de parejas de hecho que se ven abogadas a acudir a un proceso declarativo en aras a garantizar sus legítimos derechos cuando el objeto de controversia es un animal de compañía. Esto es así por cuanto los artículos $234-4$ y ss $^{40}$ del Libro Segundo del Código Civil de Cataluña relativo a la persona y la familia, no contienen regulación expresa para que los Tribunales puedan regular acerca de la tenencia y cuidados del animal de compañía tras una crisis de pareja toda vez que

miembros de la familia y al bienestar del animal, si los animales de compañía se confían a uno o a ambos cónyuges, la forma en que el cónyuge al que no se hayan confiado podrá tenerlos en su compañía, así como también las medidas cautelares convenientes para conservar el derecho de cada uno."

${ }^{37}$ Vid. https://www.fundacion-affinity.org/animalesnosoncosas/

${ }^{38}$ FAVRE, D., GIMÉNEZ-CANDELA, T. (eds.), Animales y Derecho, Tirant lo Blanch (Valencia 2015), vid. 221 y ss. y GIMÉNEZ CANDELA, T., Descosificación de los animales en el Cc. Español, en dA Derecho Animal (Forum of Animal Law Studies) 9/3 (2018) 7-27.

39 En este sentido, vid. https://www.lavanguardia.com/natural/20180321/441737383520/perro-tendencia-compartida.html y https://www.diarimes.com/es/noticias/oci/animales/2018/03/23/una_perra_disfrutara_custodia_compartida_despues_la_separacion_ sus_propietarios_36023_3071.html

${ }^{40} \mathrm{El}$ art. 234-6 CCCat prevé "1. Tras el cese de la convivencia, los convivientes pueden acordar los efectos de la extinción de la pareja estable. 2. En el caso de acuerdos alcanzados tras el cese de la convivencia, los convivientes de común acuerdo o uno de los convivientes con el consentimiento del otro pueden someter a la aprobación de la autoridad judicial una propuesta de convenio que incluya todos los efectos que la extinción deba producir respecto a los hijos comunes y entre los convivientes. A los acuerdos incluidos en una propuesta de convenio se les aplica el artículo 233-3. 3. Si no existen hijos comunes que dependen de los convivientes, estos pueden regular los efectos de la extinción de la pareja estable por medio de un convenio formulado ante el letrado de la Administración de Justicia o en escritura pública ante notario. 4. Los acuerdos alcanzados fuera de convenio se rigen por el artículo 233-5. 5. Si no existe acuerdo entre los convivientes, se aplica lo establecido por el artículo 233-4". 
se le sigue aplicando el régimen jurídico establecido en el Libro Quinto del Código Civil de Cataluña, circunstancia ésta que genera que en caso de ruptura de pareja de hecho, los litigantes no pueden acudir a un proceso de familia para dirimir la cuestión de la tenencia y cuidados del animal de compañía, por ser una cuestión no prevista en nuestro ordenamiento jurídico para tales procesos relativos a la familia, toda vez que, en caso de no existir acuerdo entre los convivientes o de existir acuerdo incluidos en una propuesta de convenio, se hace una remisión expresa a los preceptos relativos a los efectos de nulidad del matrimonio, del divorcio y de la separación legal, del que también se excluye la incorporación de pactos o regulación acerca de los animales de compañía por no constar debidamente tipificado en nuestro CCCat.

Pese ello, dicha solución de acordar la tenencia compartida del animal de compañía ha sido ya previamente alcanzada por otros Tribunales, a los que no debe desmerecerse sus esfuerzos tales como el Juzgado de Badajoz o Valladolid en las sentencias de JPI $n^{\circ} 2$ Badajoz, 7.10.2020 (MP: Luis Romualdo Hernández Díaz-Ambrona) ${ }^{41}$ y JPI no 9 Valladolid, 27.5.2019 (MP: Luis Carlos Tejedor Muñoz) ${ }^{42}$.

En tanto lo anterior, podemos concluir que, en procesos declarativos tras una ruptura de pareja de hecho, los Tribunales han flexibilizado la rigidez del régimen jurídico de los animales de compañía para adaptarlo a la nueva consciencia social pese a la formulación negativa. Si bien no existe una doctrina pacífica y consolidada acerca de la regulación de los animales de compañía en materia de crisis de pareja, si se ha atendido en mayor o menor medida a la sentiencia animal al considerar que los animales de compañía crean lazos afectivos con la familia y son seres vivos dotados de sensibilidad física y psíquica, debiéndose hacer especial referencia en este punto a la Declaración de Cambridge (2012) por ser el primer manifiesto escrito por científicos que reconocen que los humanos no somos los únicos en poseer la base neurológica que da lugar a la consciencia y por lo tanto, los animales son conscientes de su situación, capaces de experimentar y realizar comportamientos intencionales ${ }^{43}$.

Y todo ello refuerza en la necesidad de modernizar nuestros códigos mediante una reforma legislativa dado el vacío legal existente en materia de regulación de animales de compañía cuando media una ruptura sentimental, a los efectos de garantizar el bienestar animal.

Por ello, y dado el interés jurídico cada vez mayor de tratar cuestiones donde el objeto de controversia versa únicamente sobre el animal de compañía, los Juzgadores en ambas resoluciones judiciales analizadas, han atendido a declarar la copropiedad del animal y, por ende, la tenencia compartida del mismo, en aras a buscar una solución jurídica que se adecue a la constante evolución y necesidades de la sociedad.

\section{Referencias}

\section{Bibliografía y artículos en revistas}

- CASAS DÍAZ L., CAMPS I VIDELLET X., Las crisis matrimoniales y los animales de compañía: una aproximación práctica desde el ejercicio de la abogacía. dA. Derecho Animal (Forum of Animal Law Studies) 10/1 (2019). https://doi.org/10.5565/rev/da.397

- CERDEIRA BRAVO DE MANSILLA, G., Crisis familiares y animales domésticos Reus (Madrid 2020).

- FAVRE, D., GIMÉNEZ-CANDELA, T. (eds.), Animales y Derecho, Tirant lo Blanch (Valencia 2015)

- GIMÉNEZ-CANDELA, T., Derecho privado romano, Tirant lo Blanch (Valencia 2020)

- GIMÉNEZ-CANDELA, T., Transición animal en España, Tirant lo Blanch (Valencia 2020)

- GIMÉNEZ CANDELA, T., La Descosificación de los animales (I) y (II), en dA Derecho Animal (Forum of Animal Law Studies) 8/2 y 8/3 (2017). https://doi.org/10.5565/rev/da.250

- GIMÉNEZ CANDELA, T., Descosificación de los animales en el Cc. Español, en dA Derecho Animal (Forum of Animal Law Studies) 9/3 (2018) 7-27. https://doi.org/10.5565/rev/da.361

- GIMÉNEZ-CANDELA, T., Dignidad, Sentiencia, Personalidad: relación jurídica humano-animal, en dA Derecho Animal (Forum of Animal Law Studies) 9/2 (2018). DOI: https://doi.org/10.5565/rev/da.346

- GIMENO RUIZ, A., Reforma de la legislación civil sobre el régimen jurídico de los animales y Derecho Internacional Privado, en dA Derecho Animal (Forum of Animal Law Studies) 10/2 (2019) 209-216. https://doi.org/10.5565/rev/da.428

- SILlERO CROVETTO, B., Animales de compañía y crisis matrimoniales: marco normativo y

\footnotetext{
${ }^{41}$ Disponible en: http://www.poderjudicial.es/search/AN/openDocument/1bda2019841b8f70/20101021

${ }^{42}$ Disponible en: http://www.poderjudicial.es/search/AN/openDocument/6535bflc33d86882/20190606

${ }^{43}$ Vid. http://www.fcmconference.org/
} 
decisiones judiciales, en Diario La Ley no 9532 (2019).

\section{Legislación}

- España. Real Decreto de 24 de julio de 1889, por el que se publica el Código Civil. Disponible en: https://www.boe.es/eli/es/rd/1889/07/24/(1)/con

- Cataluña. Ley 5/2006, de 10 de mayo, del Libro Quinto del Código civil de Cataluña, relativo a los derechos reales. Disponible en: https://www.boe.es/eli/es-ct/1/2006/05/10/5/con

- Cataluña. Ley 25/2010, de 29 de julio, del Libro Segundo del Código civil de Cataluña, relativo a la persona y la familia. Disponible en: https://www.boe.es/eli/es-ct/1/2010/07/29/25/con

- Cataluña. Decreto Legislativo 2/2008, de 15 de abril, por el que se aprueba el Texto refundido de la Ley de protección de los animales. Disponible en: https://portaljuridic.gencat.cat/eli/esct $/ \mathrm{d} \lg / 2008 / 04 / 15 / 2$

- Unión Europea. Tratado Funcionamiento de la Unión Europea. Disponible en: http://data.europa.eu/eli/treaty/tfeu_2012/oj

- Portugal. DL n. ${ }^{\circ}$ 47344/66, de 25 de Novembro, Código Civil. Disponible en: http://www.pgdlisboa.pt/leis/lei_mostra_articulado.php?nid=775\&tabela=leis

- Colombia. Ley 84 de 1873, de 27 de mayo del Código civil de Colombia. Disponible en http://www.secretariasenado.gov.co/senado/basedoc/codigo_civil.html

- Francia. Code civil. Disponible en https://www.legifrance.gouv.fr/affichCode.do?cidTexte=LEGITEXT000006070721 